\title{
Synthesis, Characterization, Properties, and Applications of Nanosized Photocatalytic Materials
}

\author{
Jiaguo Yu, ${ }^{1}$ Mietek Jaroniec, ${ }^{2}$ Huogen Yu, ${ }^{3}$ and Wenhong Fan ${ }^{4}$ \\ ${ }^{1}$ State Key Laboratory of Advanced Technology for Material Synthesis and Processing, Wuhan University of Technology, \\ Luoshi Road 122, Wuhan 430070, China \\ ${ }^{2}$ Department of Chemistry and Biochemistry, Kent State University, Kent, OH 44242, USA \\ ${ }^{3}$ Department of Chemistry, School of Science, Wuhan University of Technology, Wuhan 430070, China \\ ${ }^{4}$ School of Chemistry and Environment, Beijing University of Aeronautics and Astronautics, Beijing 100191, China
}

Correspondence should be addressed to Jiaguo Yu, jiaguoyu@yahoo.com

Received 1 October 2012; Accepted 1 October 2012

Copyright (C) 2012 Jiaguo Yu et al. This is an open access article distributed under the Creative Commons Attribution License, which permits unrestricted use, distribution, and reproduction in any medium, provided the original work is properly cited.

In recent years, the research on semiconductor photocatalytic materials has attracted worldwide attention because of great significance of these materials in solving global energy and environmental problems by effective utilization of solar energy. However, the photocatalytic activity of these materials is still far from that required by commercial applications, and therefore further studies are needed in this direction. Nanostructured photocatalytic materials with novel properties (e.g., enhanced light absorption, quantum confinement, high specific surface area and tunable surfaceto-volume ratio, hierarchical porous structure, etc.) create tremendous opportunities in extending their applications in various fields including water and air purification, photocatalytic disinfection, photocatalytic hydrogen generation, and dye-sensitized solar cells [1-8].

This special issue contains sixteen papers, which mainly deal with synthesis, characterization, properties, and environmental applications of nanosized photocatalytic materials. Among them seven papers are related to environmental photocatalysis, one paper is devoted to photoelectrocatalysis and photoelectrochemistry, one paper presents photocatalytic reduction of carbon dioxide, one paper reports on dyesensitized solar cells, four papers are related to preparation and properties, and the remaining two papers deal with cancer-cell treatment and with physiological damage of daphnia magna. Furthermore, in this special issue, 14 papers are related to the doped or composite $\mathrm{TiO}_{2}$ photocatalystic materials. We wish to express our thanks to all the authors who have made this special issue possible. A brief summary of all sixteen papers is presented below.

The article on "Influence of annealing and UV irradiation on hydrophilicity of $\mathrm{Ag}-\mathrm{TiO}_{2}$ nanostructured thin films" is focused on the fabrication and UV-induced hydrophilicity of $\mathrm{Ag}-\mathrm{TiO}_{2}$ nanostructured thin films on silicon, glass, and quartz substrates by RF magnetron sputtering. The influence of annealing and UV irradiation time on the hydrophilic properties of $\mathrm{Ag}-\mathrm{TiO}_{2}$ composite thin films is studied and discussed. It is shown that the unannealed film was an amorphous phase with small hydrophilicity. The crystallite size increased slowly with increasing annealing time from 15 to $120 \mathrm{~min}$. A suitable annealing time can obviously enhance the hydrophilic behavior of $\mathrm{Ag}-\mathrm{TiO}_{2}$ composite films. The mechanism of hydrophilicity can be attributed to the increase of oxygen anion radicals $\mathrm{O}_{2}{ }^{-}$and reactive surface $\mathrm{Ti}^{3+}$ species.

Another article "Enhanced visible-light photocatalytic performance of nanosized anatase $\mathrm{TiO}_{2}$ doped with $\mathrm{CdS}$ quantum dots for cancer-cell treatment," CdS quantumdots- (QDs-) doped $\mathrm{TiO}_{2}$ composites prepared by sol-gel method were used as a new "photosensitizer" based on photodynamic therapy (PDT) for cancer-cell treatment. The photocatalytic activity of $\mathrm{CdS}-\mathrm{TiO}_{2}$ towards leukemia tumor was investigated by using Cell Counting Kit-8 (CCK-8) assay. The experimental results indicate that an obvious inhibition of tumor growth was observed in the groups treated with CdS- $\mathrm{TiO}_{2}$ composites, and the PDT efficiency was higher 
in the presence of CdS-doped $\mathrm{TiO}_{2}$ than that in the case of $\mathrm{TiO}_{2}$ only, revealing that the photocatalytic activity of $\mathrm{TiO}_{2}$ was obviously enhanced by its modification with CdS QDs. Thus, CdS- $\mathrm{TiO}_{2}$ composites can be regarded as promising materials for cancer-cell treatment.

In "Enhancement of electron transfer efficiency in solar cells based on PbS QD/N719 dye cosensitizers," the authors designed new photoanode architecture, namely, PbS QDs and N719 dye were used as co-sensitizers of the $\mathrm{TiO}_{2}$ mesoporous films. The experimental results show a significant improvement in the electron transfer efficiency when $\mathrm{PbS}$ QDs/N719 dye cosensitized structure is used, The use of $\mathrm{PbS}$ in the aforementioned structure resulted not only in the enhancement of the transfer efficiency of photo-excited electrons, but also in achieving a wider range and higher intensity of light absorption. The PbS QDs-deposited $\mathrm{TiO}_{2}$ film was coated by N719 dye, which can effectively prevent $\mathrm{PbS}$ QDs against corrosion by $\mathrm{I}^{-} / \mathrm{I}_{3}^{-}$electrolyte and light. As expected, the solar energy conversion efficiency of these photoanodes was relatively higher than that of the PbS QDs or N719 dye, single-sensitized solar cells.

In "Effect of the steam activation thermal treatment on the microstructure of continuous $\mathrm{TiO}_{2}$ fibers," the synthesis of continuous $\mathrm{TiO}_{2}$ fibers from titanate precursors by solgel method is reported. The grain growth kinetics was investigated. The results showed that the average diameters of fibers were in the range of $20-30 \mu \mathrm{m}$, the crystal phase of the synthesized $\mathrm{TiO}_{2}$ fibers was changed from anasate to rutile, and the crystal size became bigger with increasing temperature under steam activation.

In "Impact of $\mathrm{Ge}^{4+}$ ion as structural dopant of $\mathrm{Ti}^{4+}$ in anatase: crystallographic translation, photocatalytic behavior, and efficiency under UV and VIS irradiation," the preparation of $\mathrm{Ge}$-doped $\mathrm{TiO}_{2}$ nanoparticles by urea-assisted homogeneous hydrolysis of $\mathrm{TiOSO}_{4}$ and $\mathrm{GeCl}_{4}$ in an aqueous solution is described. The photocatalytic activity of all samples was determined by decomposition of Orange II dye under irradiation at $365 \mathrm{~nm}$ and $400 \mathrm{~nm}$. A moderate doping with concentration up to $2.05 \mathrm{wt} . \%$ positively influenced azo dye degradation under UV and visible light. Further improvement could not be achieved by higher Ge doping. Effect of the annealing $\left(200,400\right.$, and $\left.700^{\circ} \mathrm{C}\right)$ on photocatalysis and other properties has been also evaluated.

The article "Enhanced oxidative stress and physiological damage in Daphnia magna by copper in the presence of nano- $\mathrm{TiO}_{2}$ " examines the potential hazard of an individual nanomaterial on the $\mathrm{Cu}$ biotoxicity to aquatic organisms. Daphnia magna in the absence or presence of nano- $\mathrm{TiO}_{2}$ was exposed to $\mathrm{Cu}$. Keeping nano- $\mathrm{TiO}_{2}$ at a safe concentration could not eliminate its potential hazard. $\mathrm{Cu}$ in the presence of $\mathrm{TiO}_{2}$ induced higher levels of oxidative stress and physiological damage due to the sorption of $\mathrm{Cu}$. $\mathrm{TiO}_{2}$ also caused $\mathrm{Na}^{+} / \mathrm{K}^{+}$-ATPase inhibition possibly by impeding the $\mathrm{Na}^{+} / \mathrm{K}^{+}$transfer channel. The correlation between the biomarkers, mortality, and accumulation further showed that the overloading associated with reactive oxygen species generation caused by $\mathrm{TiO}_{2}$ contributed to deeper oxidative stress and physiological regulation, thereby causing greater toxic injury.
In "Relationship between synthesis conditions and photocatalytic activity of nanocrystalline $\mathrm{TiO}_{2}$," the sol-gel synthesis of $\mathrm{TiO}_{2}$ nanoparticles under different conditions (i.e., molar ratio of water and titanium tetraisopropoxide (TTIP), $\mathrm{pH}$, and calcination temperature) is presented. The results show that an increase in the molar ratio of water and TTIP leads to the enhanced photocatalytic activity of $\mathrm{TiO}_{2}$ nanoparticles, which is attributed to the increased specific surface area of these nanoparticles. This finding is explained by the relative increase in the size of interaggregated pores between aggregated $\mathrm{TiO}_{2}$ nanoparticles. The best photocatalytic activity of $\mathrm{TiO}_{2}$ nanoparticles was observed at acidic synthesis conditions; however, the results are not consistent with physical properties for the crystallinity and the crystallite size of $\mathrm{TiO}_{2}$ nanoparticles but rather can be explained by the presence of abundant hydroxyl groups and water molecules existing on the surface of $\mathrm{TiO}_{2}$ in acidic environment.

In "Photoelectrochemical properties of $\mathrm{Fe}_{2} \mathrm{O}_{3}$ supported on $\mathrm{TiO}_{2}$-based thin films converted from self-assembled hydrogen titanate nanotube powders," the fabrication of a photoanode from hematite $\left(\alpha-\mathrm{Fe}_{2} \mathrm{O}_{3}\right)$ nanoparticles entrapped in a thin film of hydrogen titanate nanotubes $(\mathrm{H}-$ TiNT) is reported; H-TiNT were synthesized by repetitive self-assembly on FTO (fluorine-doped tin oxide) glass. The current-voltage (I-V) electrochemical properties were evaluated under ultraviolet-visible light irradiation for the heat-treated photoanode at $500^{\circ} \mathrm{C}$ for $10 \mathrm{~min}$ in air. The prepared $\mathrm{Fe}_{2} \mathrm{O}_{3} / \mathrm{H}$-TiNT/FTO composite thin film exhibited photocurrent threefold higher than that measured for the $\mathrm{Fe}_{2} \mathrm{O}_{3} / \mathrm{FTO}$ film. The observed improvement in photocurrent was related to the reduced recombination of electrons and holes, with an appropriate amount of $\mathrm{Fe}_{2} \mathrm{O}_{3}$ spherical nanoparticles supported on the H-TiNT/FTO film.

In "MWCNT-based $\mathrm{Ag}_{2} \mathrm{~S}-\mathrm{TiO}_{2}$ nanocomposites photocatalyst: ultrasound-assisted synthesis, characterization, and enhanced catalytic efficiency," the ultrasound-assisted synthesis of multiwalled carbon nanotube-based nanoscale $\mathrm{Ag}_{2} \mathrm{~S}$ and $\mathrm{TiO}_{2}$ composites is presented. The $\mathrm{Ag}_{2} \mathrm{~S}-\mathrm{TiO}_{2} / \mathrm{CNT}$ composites exhibited much higher photocatalytic activity than pure $\mathrm{TiO}_{2}$ for the degradation of Rhodamine B (Rh.B) under UV and visible light. The improved photocatalytic activity was attributed to the increased adsorption of Rh.B molecules and increased charge transfer rate in the presence of a one-dimensional MWCNT network.

The article "Dispersion and stabilization of photocatalytic $\mathrm{TiO}_{2}$ nanoparticles in aqueous suspension for coatings applications" reports the study of dispersion and stabilization of $\mathrm{TiO}_{2}$ nanoparticles in aqueous suspensions using two common dispersants polyacrylic acid (PAA) and ammonium polymethacrylate (Darvan C). The effect of various factors such as ultrasonication amplitude, type and amount of dispersants on the dispersibility, and stability of $\mathrm{TiO}_{2}$ aqueous suspensions were examined. This study shows that the addition of dispersants improves the dispersibility and stabilization of aqueous suspensions. The latter were then coated on a quartz glass, and the photocatalytic activity of the coatings was studied by degradation of formaldehyde gas under UV light. 
The aim of the research reported in "Degradation of semiconductor manufacturing wastewater by using a novel magnetic composite $\mathrm{TiO}_{2} / \mathrm{Fe}_{3} \mathrm{O}_{4}$ photoreactor design," was to develop a photocatalytic $\mathrm{TiO}_{2}$ that can be activated by visible light and can be reused. The 20 to $40 \mathrm{~nm}$ $\mathrm{TiO}_{2} / \mathrm{Fe}_{3} \mathrm{O}_{4}$ particles with magnetization of $5.8 \mathrm{emu} / \mathrm{g}$ were prepared by modified sol-gel method followed by $500^{\circ} \mathrm{C}$ calcination. The data indicate that visible fluorescent light (VFL, contains no UV-A) can activate the photocatalytic activity of $\mathrm{TiO}_{2} / \mathrm{Fe}_{3} \mathrm{O}_{4}$ particles as ultraviolet A light (UVA, $360 \mathrm{~nm}$ ) do. Regular magnets can be used to separate $\mathrm{TiO}_{2} / \mathrm{Fe}_{3} \mathrm{O}_{4}$ particles from solution. The results indicate that VFL-irradiated $\mathrm{TiO}_{2} / \mathrm{Fe}_{3} \mathrm{O}_{4}$ particles could decompose isopropanol (IPA) in the absence of UV-A.

In "Highly ordered $\mathrm{TiO}_{2}$ macropore arrays as transparent photocatalysts," the preparation of highly ordered transparent $\mathrm{TiO}_{2}$ macropore arrays by a simple glass-clamping method at ambient temperature is described. The prepared $\mathrm{TiO}_{2}$ macropore arrays showed high transmittance in the visible light region and were used as transparent photocatalysts for degradation of organic dyes.

The article "Influence of selected alkoxysilanes on dispersive properties and surface chemistry of titanium dioxide and $\mathrm{TiO}_{2}-\mathrm{SiO}_{2}$ composite Material" reports characterization of $\mathrm{TiO}_{2}$ and coprecipitated $\mathrm{TiO}_{2}-\mathrm{SiO}_{2}$ composite material functionalized with selected alkoxysilanes. This composite material was obtained by an emulsion method using cyclohexane as an organic phase, titanium sulfate as titanium precursor, and sodium silicate solution as precipitating agent. The functionalized $\mathrm{TiO}_{2}$ and $\mathrm{TiO}_{2}-\mathrm{SiO}_{2}$ composite materials were characterized to determine the yield of functionalization with silanes.

In "Immobilized $\mathrm{TiO}_{2}$ for phenol degradation in a pilotscale photocatalytic reactor," phenol degradation, which was carried out in a photocatalytic pilot plant reactor equipped with a UV/vis mercury lamp, is presented. The total volume of treated water was equal to $1.35 \mathrm{~m}^{3}$. $\mathrm{TiO}_{2} \mathrm{P} 25$ was used as a photocatalyst and it was immobilized on two different supports: (i) a steel mesh and (ii) a fiberglass cloth. The highest effectiveness of phenol decomposition and mineralization was observed in the presence of $\mathrm{TiO}_{2}$ supported on the fiberglass cloth. After $15 \mathrm{~h}$ of the process, phenol and total organic carbon concentrations decreased by ca. 80 and $50 \%$, respectively.

In "Effect of preparation parameters on photoactivity of $\mathrm{BiVO}_{4}$ by hydrothermal method," the hydrothermal synthesis of bismuth vanadate $\left(\mathrm{BiVO}_{4}\right)$ from $\mathrm{Bi}\left(\mathrm{NO}_{3}\right)_{3}$ and $\mathrm{NH}_{4} \mathrm{VO}_{3}$ is reported. Based on orthogonal and single factor experiments, the optimal synthetic parameters were determined. The results indicate that the optimal experimental parameters for the preparation of monoclinic $\mathrm{BiVO}_{4}$ are $\mathrm{pH}=7,195^{\circ} \mathrm{C}$ and $6 \mathrm{~h}$. The catalytic performance of $\mathrm{BiVO}_{4}$ was evaluated by reducing carbon dioxide to methane under visible light irradiation. It was found that the methane production reached $145 \mu \mathrm{g} / \mathrm{g}$-cat after $5 \mathrm{~h}$ irradiation.

In "Structural characterisation of $\mathrm{ZnO}$ particles obtained by the emulsion precipitation method," the precipitation of zinc oxide in an emulsion system by using zinc acetate as a precursor of $\mathrm{ZnO}$ and potassium hydroxide or sodium hydroxide as precipitating agents is described. Cyclohexane, as an organic phase, and a nonionic surfactant were also used for preparation of the emulsion. Additional modifications of the $\mathrm{ZnO}$ precipitation process, involving for instance different precipitating agents, and/or changes in the composition of substrates and in the dosing rate of substrates, afforded some interesting structures of $\mathrm{ZnO}$ particles. For selected samples their electrical properties (dielectric permittivity and electric conductivity) were also measured. The resulting zinc oxide consisted of particles in the form of ellipsoids, rods, and flakes with sizes ranging from about 160 to $2670 \mathrm{~nm}$ and showed the well-developed surface area reaching $20 \mathrm{~m}^{2} / \mathrm{g}$.

The above synopsis of the articles collected in this special issue on synthesis, characterization, properties, and applications of nanosized photocatalytic materials indicates that this area of research is continuously expanding. Our hope is this special issue will stimulate further developments in the field of photocatalytic materials.

\section{Jiaguo $\mathrm{Yu}$ \\ Mietek Jaroniec \\ Huogen $\mathrm{Yu}$ \\ Wenhong Fan}

\section{References}

[1] J. G. Yu, M. Jaroniec, and G. X. Lu, " $\mathrm{TiO}_{2}$ photocatalytic materials," International Journal of Photoenergy, vol. 2012, Article ID 206183, 5 pages, 2012.

[2] Q. J. Xiang, J. G. Yu, and M. Jaroniec, "Graphene-based semiconductor photocatalysts," Chemical Society Reviews, vol. 41, pp. 782-796, 2012.

[3] Q. J. Xiang, J. G. Yu, and M. Jaroniec, "Synergetic effect of $\mathrm{MoS}_{2}$ and graphene as cocatalysts for enhanced photocatalytic $\mathrm{H}_{2}$ production activity of $\mathrm{TiO}_{2}$ nanoparticles," Journal of the American Chemical Society, vol. 134, pp. 6575-6578, 2012.

[4] X. M. Zhou, G. Liu, J. G. Yu, and W. H. Fan, "Surface plasmon resonance-mediated photocatalysis by noble metalbased composites under visible light," Journal of Materials Chemistry, vol. 22, pp. 21337-21354, 2012.

[5] J. Zhang, J. G. Yu, M. Jaroniec, and J. R. Gong, "Noble metalfree reduced graphene oxide- $\mathrm{Zn}_{x} \mathrm{Cd}_{1-x} \mathrm{~S}$ nanocomposite with enhanced solar photocatalytic $\mathrm{H}_{2}$ - production performance," Nano Letters, vol. 12, pp. 4584-4589, 2012.

[6] J. Zhang, J. G. Yu, Y. M. Zhang, Q. Li, and J. R. Gong, "Visible light photocatalytic $\mathrm{H}_{2}$-production activity of $\mathrm{CuS} / \mathrm{ZnS}$ porous nanosheets based on photoinduced interfacial charge transfer," Nano Letters, vol. 11, pp. 4774-4779, 2011.

[7] Q. Li, B. Guo, J. Yu et al., "Highly efficient visible-light-driven photocatalytic hydrogen production of CdS-cluster-decorated graphene nanosheets," Journal of the American Chemical Society, vol. 133, no. 28, pp. 10878-10884, 2011.

[8] S. W. Liu, J. G. Yu, and M. Jaroniec, "Anatase $\mathrm{TiO}_{2}$ with dominant high-energy 001 facets: synthesis, properties, and applications," Chemistry of Materials, vol. 23, pp. 4085-4093, 2011. 

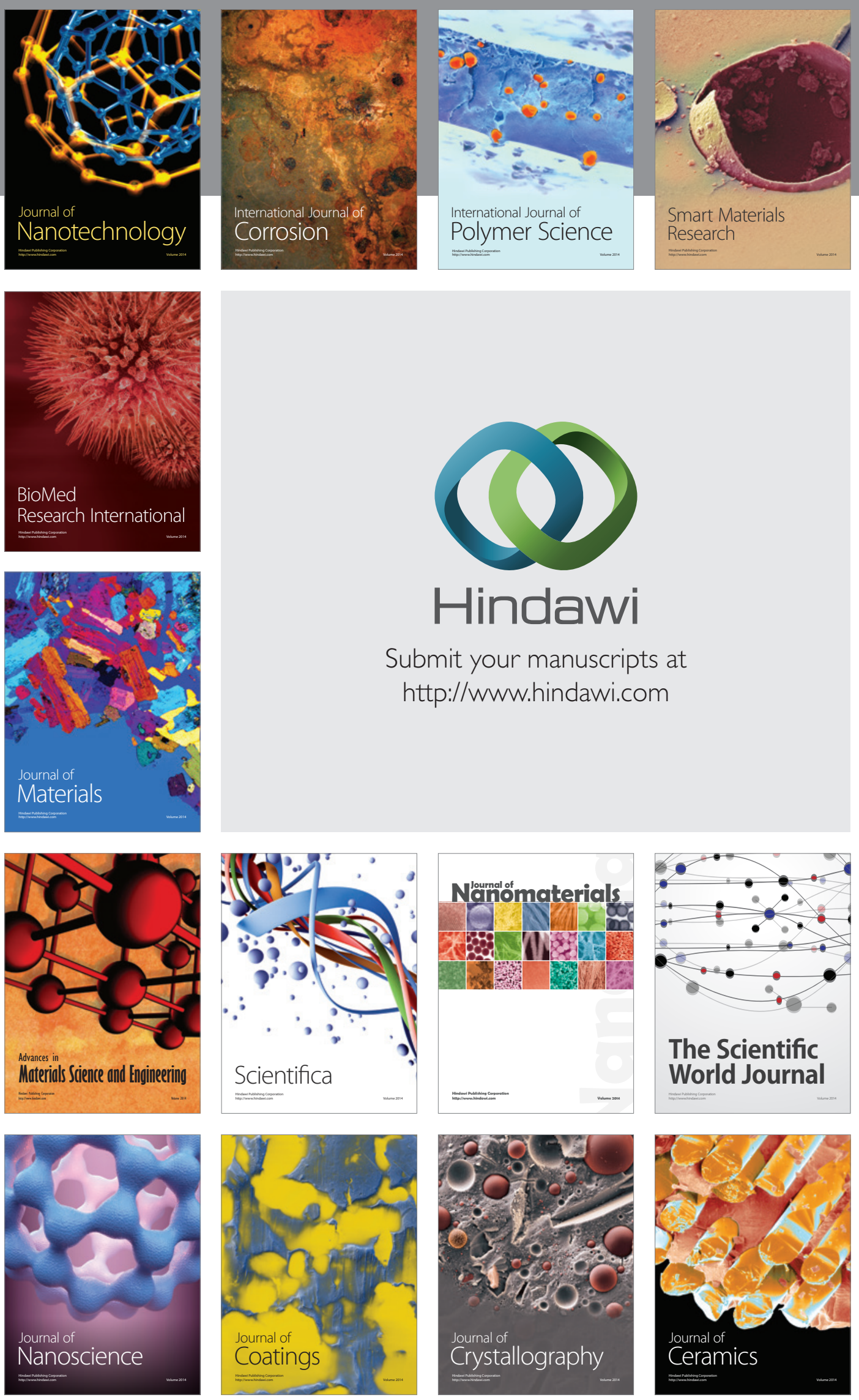

The Scientific World Journal

Submit your manuscripts at

http://www.hindawi.com

\section{World Journal}

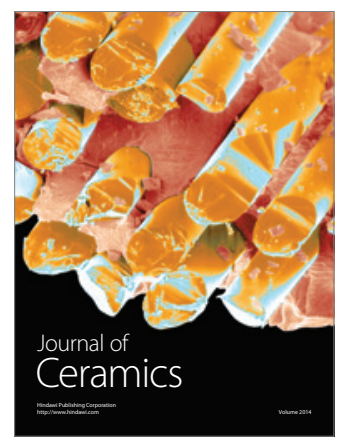

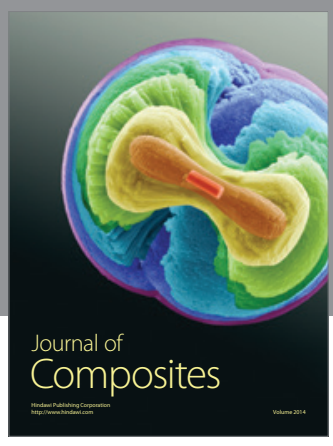
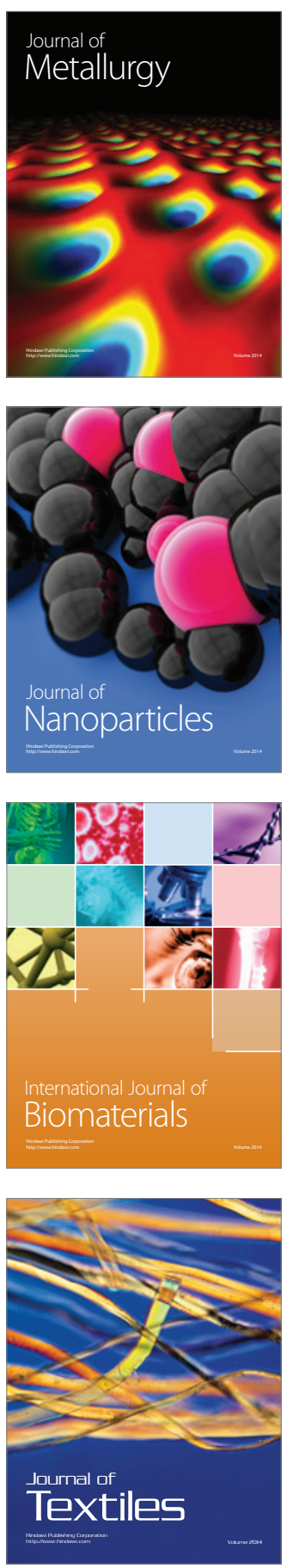